\title{
A PROTECTIVE SAFETY FOOTWEAR DEVICE SIMULATION AND DESIGN: AN INNOVATIVE AND HEALTHY HYBRID COMPONENT
}

\author{
Joel Vieira da Silva \\ MEtRICs, Department of Mechanical Engineering, \\ University of Minho \\ 4800-058 Guimarães, Portugal \\ Maria José Abreu \\ 2C2T, Dept. Textile Engineer \\ University of Minho \\ 4800-058 Guimarães, Portugal
}

\author{
Sergio L. Costa \\ MEtRICs, Department of Mechanical Engineering, \\ University of Minho \\ 4800-058 Guimarães, Portugal \\ Joao P. Mendonca \\ MEtRICs, Department of Mechanical Engineering, \\ University of Minho \\ 4800-058 Guimarães, Portugal
}

\begin{abstract}
The use of Personal Protective Equipment (PPE) has become a necessity in view of the number of accidents at work that occurred in the past years. The European Community (EU) and the member states are creating strategies aiming the increase of the use of PPE's and consequently the decrease of the number of the accidents at work, decreasing also the number of injuries caused by them and their severity. In this paper, a brief review of safety footwear and its components will be presented focusing on penetration resistant inserts. Additionally, we present a project in development at University of Minho that aims to improve the existent shoes. This project proposes a brand new penetration resistant inserts through a combination of innovative materials.
\end{abstract}

\section{INTRODUCTION}

According to the European Statistics on Accidents at Work (ESAW), every year in the EU, about 3 million workers were victims of accidents at work leading to more than three days of absence from work; Additionally, about 5000 workers died in accidents at work (Communities, 2004)

The European Union (EU) along with the member states are creating strategies aiming the increase of the use of PPE's and consequently the decrease of the number of accidents at work.
In 2010 there were about 2634196 accidents at work in Europe of which 707292 affected the lower extremities (EUROSTAT, 2013).

During the same period of time, in Portugal, the numbers were equally large; 215632 accidents of which 52467 affected lower extremities Table 1 shows the evolution of accidents at work according to the nature of the worker injury between 2002 and 2010. Despite the substantial decrease of the number of injuries in legs and feet after the adoption of the Community Strategy on Health and Safety at work in March 2002, there was a decrease on the rate of serious injuries such as internal injuries and member's amputations. This fact led to an increase in the minor injuries.

In Portugal, these type of accidents leads to an incapacity of the employee to work for normally 15 days. Besides the human suffering, these accidents have a heavy impact on productivity and consequently financial losses.

Although there is a positive trend towards the use of PPE's, in particular safety footwear, presently, a large number of employees still neglect the use of this kind of protection. Goldcher and Acker in 2005 were able to present some reasons for the fact above mentioned:

- Uncomfortable at work;

- Excessive weight, which lead to muscle fatigue at the end of the day (heel pain, calf pain);

- Lack of flexibility due to the reinforcement of the base;

- Models unsuited to the morphology of some feet; 
- Occurrence of foot injuries, in part secondary to the previous two complaints: redness, blistering, hyperkeratosis, among others;

- Lack of aesthetic and ergonomics;

- Inadequate ventilation which promote sweating, maceration and fungal infection.

With this in mind, it is necessary to improve the safety footwear available in order to be accepted by a larger number of employees, thereby reducing the number of accidents at work and the financial losses that affects both employers and employees.

\section{SAFETY FOOTWEAR INDUSTRY}

The safety footwear industry has suffered improvements in order to increase the level of the user's comfort and to decrease the manufacturing costs of the safety shoe and it's components.

This development can be considered to have evolved in three different ways: manufacturing process, materials and design.

Once the reliability of a safety shoe not depends only on the safety components, but also in the shoe structure where it's inserted, it becomes important to ensure the production of a steady and comfortable shoe. With advances in the insole and outsole materials and the remaining shoe components as well as the advances in the production processes, it is now possible to produce footwear with high quality and most competitive prices. Materials of toecap and penetration resistant inserts are another way of evolution for safety footwear. The most common material for these components is the steel since it offers the best price and better mechanical properties, however, in the past, steel has been losing its importance to other materials such as aluminum or composite materials. These materials have the advantage of being lighter, but on the other hand they need to have higher thickness and size to confer the same protection as steel. Flexible materials such as aramide based structures have became very used in protection insoles because they offer a higher comfort level and they have the advantage of being metal free. (Sartor, 2008)

Table 1. Basic requirements of Personal Protective shoes. Adapted from (Goldcher \& Acker, 2005)

\begin{tabular}{|c|c|c|c|c|c|c|c|c|c|c|c|c|c|c|c|c|c|}
\hline \multirow{3}{*}{ Level of protection } & \multicolumn{6}{|c|}{ EN ISO 20345} & \multicolumn{6}{|c|}{ EN ISO 20346} & \multicolumn{5}{|c|}{ EN ISO 20347} \\
\hline & \multicolumn{6}{|c|}{ Safety Footwear } & \multicolumn{6}{|c|}{ Protective Footwear } & \multicolumn{5}{|c|}{ Occupational Footwear } \\
\hline & $\mathrm{SB}^{\mathrm{a}}$ & $\mathrm{S} 1^{\mathrm{c}}$ & $\mathrm{S} 2^{\mathrm{c}}$ & $\mathrm{S} 3^{\mathrm{c}}$ & $S 4^{d}$ & $\mathrm{~S} 5^{\mathrm{d}}$ & $\mathrm{PB}^{\mathrm{b}}$ & $\mathrm{P} 1^{\mathrm{c}}$ & $\mathrm{P} 2^{\mathrm{c}}$ & $\mathrm{P} 3^{\mathrm{c}}$ & $\mathrm{P} 4^{\mathrm{d}}$ & $\mathrm{P} 5^{\mathrm{d}}$ & $\mathrm{O} 1^{\mathrm{c}}$ & $\mathrm{O} 2^{\mathrm{c}}$ & $\mathrm{O}^{\mathrm{c}}$ & $\mathrm{O} 4^{\mathrm{d}}$ & $\mathrm{O} 5^{\mathrm{c}}$ \\
\hline Basic protection & + & + & + & + & + & + & + & + & + & + & + & + & + & + & + & + & + \\
\hline Closed seat region & & + & + & + & & & & + & + & + & & & + & + & + & & \\
\hline Antistatic properties & & + & + & + & + & + & & + & + & + & + & + & + & + & + & + & + \\
\hline Energy absorption of hell & & + & + & + & + & + & & + & + & + & + & + & + & + & + & + & + \\
\hline $\begin{array}{l}\text { Water penetration } \\
\text { resistance }\end{array}$ & & & + & + & & & & & + & & & & & & + & & \\
\hline Penetration Resistance & & & & + & & & & & & + & & + & & & + & & \\
\hline Cleated outsole & & & & + & & & & & & + & & + & + & & + & & \\
\hline
\end{tabular}

At last but not least, there was an evolution in the safety components design. Nowadays there are a larger number of shapes than few years ago. The design change of this component allowed the development of safety footwear for various situations, making the safety shoes no longer restricted in terms of fashion design and style. Costa, et al.in 2013 shows a redesign of a toe cap component. Currently it is possible to find in the market casual shoes, sports shoes and even lady boots with a high level of protection. The companies in this sector have given a great importance to this subject, allowing the improvement of the ergonomics, comfort, cost and de-sign of the final product. This leads these companies to engage in creating strategies that ensure the reduction of development time for these products.

\section{A. SAFETY SHOES}

Shoes with suitable protection have improved in order to protect the employee foot of all the environmental risks. There are various types of injuries and the most common are:

- Fall by slipping;

- Injuries in toes due to falling objects;

- Crushing toes by heavy vehicles;

- Piercing the foot by sharp objects resulting in internal injuries and severe infections;

So, penetration resistant inserts and toecaps are the most important components of safety shoes.

The penetration resistant inserts should also prevent injuries in the heel, metatarsal and muscles of the foot.

According to the legislation, there are various types of protective footwear classified according to the protection that they offer: as safety shoes, protection shoes and occupational shoes.

The type of protection conferred by any of the above mentioned types of shoes is shown in Table. In this table, the numbers are related to the level of protection offered by the shoes. 
The letters are related to the type of shoes, $S$ for safety shoes, $\mathrm{P}$ for protective shoes and $\mathrm{O}$ for occupational shoes. $\mathrm{SB}^{\mathrm{a}}$ and $\mathrm{PB}^{\mathrm{b}}$ refers to all materials that compose the shoe. $\mathrm{S}^{\mathrm{c},} \mathrm{P}^{\mathrm{c}}$ and $\mathrm{O}^{\mathrm{c}}$ are related to shoes made from all materials, except natural or synthetic polymers and $\mathrm{S}^{\mathrm{d}}, \mathrm{P}^{\mathrm{d}}$ and $\mathrm{O}^{\mathrm{d}}$ are related to shoes made from natural and synthetic polymers.

The main difference between safety, protective and occupational shoes is the toecap protection. In the case of safety shoes, toecaps must resist to a mechanical impact of $200 \mathrm{~J}$, while the impact supported by the protective shoes should be $100 \mathrm{~J}$. In the case of the occupational shoes, the toecap protection is not required.

\section{B. PENETRATION RESISTANT INSERTS}

As one of the most important components of protection footwear, the principal function of penetration resistant inserts is to prevent the penetration of sharp objects. This occurs in almost every industrial sector, but mainly in the construction sector.

Initially it was only possible to confer protection against penetration using steel plates of great thick-ness, which made the safety shoe rigid and extremely uncomfortable. In order to optimize the comfort and the protection level at the same time, these components evolved in terms of materials and thicknesses. Nowadays it is possible to find in the market penetration resistant inserts with a wide range of materials and structures.

Of the existing anti-penetration inserts the most used by the industry are metallic or made of aramid fibers (Kevlar ${ }^{\circledR}$ or Twaron ${ }^{\circledR}$ ). Metallic inserts have a thickness of $\approx 0.5 \mathrm{~mm}$ and are still very used since they have a low cost production. The aramid fiber inserts are very flexible, what makes the shoe more comfortable, but on the other hand, their cost is superior to the metallic inserts. In the market, are also available inserts made from composite materials or made from the combination of materials, but they are patented.

In 1991, Kenji Okayasu, (Okayasu, 1991) developed a new penetration resistant insert aiming the improvement of the flexibility of the existent inserts. Okayasu used small metal plates joined together al-lowing the insert to bend in the front part, the metal plates are involved in an involcro from plastic or rubber in order to prevent the insert damaging in the sole of the shoe. The main disadvantages of this insert are it complex manufacture process and the fact that it flexibility inflict restrictions in the movement of the foot.

In 1994, Albertus Aleven (ALEVEN, 1994) developed a insert composed by four layers. This insert provides for the first time stiffness and flexibility in different parts of the insert. The first layer is a olymeric protector layer with a specific protector zone of stainless steel in the front part of the insert. The joint between this two layers is the area where the foot will bend while walking, allowing the caused tension to be absorved by the polymeric layer. The insert has an upper layer made of a fabric with anti-fungal properties and a bottom layer made of polyester. The variation of the thickness through-out the insert area allows the optimization of the flexibility in the required areas. The disadvantage of this type of insert is it complex and expensive manufacture process, additionally, with the use of the shoes, the metallic and the polymeric layers can be separated, leaving an area of the foot vulnerable to sharp objects.

In 1999, Frederick Harrison (Harrison, 1999) developed a polymeric penetration resistant insert that has a toecap and a special area to protect the heel. The main advantage of this insert is the fact that in the manufacture process of the shoe, the steps of the assemble of the toecap is eliminated once this component is already a part of the insert. This insert is made of a polymer capable of absorb a great amount of energy and comfer a good flexibility. A metallic plate is assembled in the polymer in order to improve the protection level of the insert, however, this metallic plate provide to much stiffness to the insert.

In 2003, Luigi Bettaglia (Battaglia, 2003) present-ed an improvement of the simple metallic inserts by applying longitudinal ribs in the back part of the insert, which form on the upper surface of the sole grooved ribs protruding from the opposite surfaces so as to form the convexities. These channels, stiffens the area between the heel and the arch of the foot, giving it greater resistance to flexion and torsion.

In 2008, Leo Sartor and his collegues (SARTOR, 2008) developed a insert with two distinct parts. The front part of the insert is comprised of multiple layers of aramide fiber conferring a good flexibility. The back part of the insert is made of a composite material and acts like a structural element and pre-vents the heel torsion and therefore heel injuries. This insert combines for the first time the advantages of the metallic inserts and the advantages of the inserts made of aramide fibers. The disadvantage of Leo Sartor insert is the complex manufacture process.

\section{DEVELOPMENT OF A NEW PENETRATION RESISTANT INSERT}

With the improvement of safety footwear in mind, the main goal of the mentioned research is the development of a new penetration resistant insert. For that were studied the most used commercial penetration resistant inserts. Several tests were performed in order to completely characterize the inserts. The most important was the penetration resistant test, these results allowed to find a brand new solution with an innovative combination of metallic and polymeric materials.

\section{A. BENCHMARKING}

A detailed analysis of the existing commercial inserts was being carried out, whose results are going to be presented below.

The anti-penetration inserts still have several flaws that undermine the comfort and reliability of safety shoes. In order to improve this component, this work aims the development of a new and innovative penetration resistant insert that can be more acceptable by the workers. 
The starting point of this study was a detailed analysis of the inserts available in the market, whose results allowed us to understand what the most important characteristics of the inserts are. Thus, we were able to conclude that the properties imposed by the safety shoes standards are: penetration resistance; anti-corrosion and fatigue resistance; the main properties are flexibility in the frontal zone of the insert and anti-torsion in the heel zone; and at last, the secondary properties of the penetration resistant inserts are protection against heel injuries, anti-fungi properties, lateral protection, low thickness, permeability, good adhesion to the outsole, low weight, be metal free and impact damping. With these properties in mind, we were able to create a relation between the main properties of the inserts and the area of the foot where they are required as can be seen in Table 2 .

Table 2. Relation between the characteristics of the inserts and the foot area where they are required.

$\frac{\text { Characteristics }}{\text { Flexibility }}$

\section{Anti-torsion}

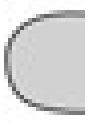

\section{Heel protection}

\section{Confort}
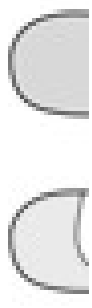

\section{Adhesion to outsole}

The analysis of Table 2 shows that there is a need to provide different properties in different areas of the foot. To provide those properties, materials with different stiffness will be need. In resume this table shows the need of a hybrid insert, where several materials must work together in the protection of the different areas of the foot.

\section{B. PENETRATION TESTS}

Therefore, destructive tests were performed to the normally used materials. The penetration tests were performed according to the methodology described in European standard EN 12568-2010. These tests were made in several commercial metallic and aramid fiber inserts from different brands and producers. The selected inserts are produced in different continents, one of them is from North-America, another from South-America and three from Europe. All of them are certificated according European standards and are currently used in different shoe's brands. The graph in Figure 1 shows the results of metallic inserts from five different producers.

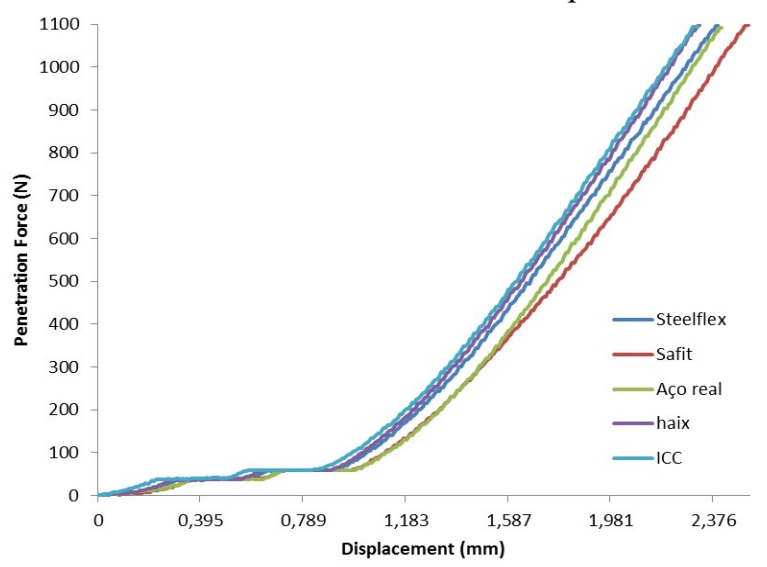

Figure 1. Comparison between mechanical behavior of different metallic penetration resistant inserts.

In the abscissas axis is shown the displacement of the sharp object and the ordinate axis shows the penetration force. As it can be seen in the previous graph, all metallic inserts tested have a very similar performance. This can be justified through chemical composition of the materials, which is similar as well.

The Figure 2 shows a comparison between a metallic (stainless steel) and a polymer (aramid fiber) insert.

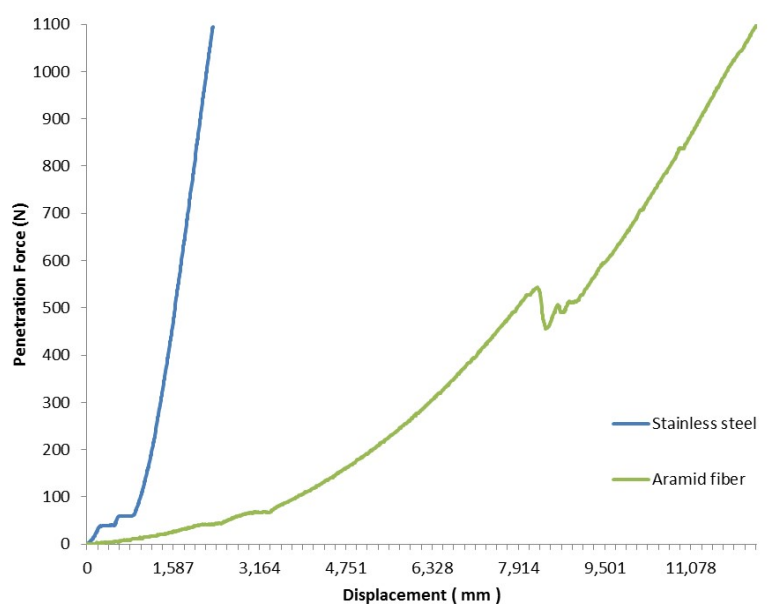

Figure 2. Comparison between mechanical behavior of metallic and polymeric penetration resistant inserts.

The results show that although polymeric inserts have passed the test, they have a large displacement comparing with the metallic inserts. The displacement of the sharp object isn't specified in used European standards, but it should be considered. A high displacement may cause serious injuries in the heel zone or superficial injuries in frontal zone. As was 
shown, the displacement of aramid fiber insert is more than 10 $\mathrm{mm}$, this value is significantly high.

The analysis of this information allows concluding that there is an important difference between the mechanical performance of metallic and polymeric inserts. Metallic inserts are better penetration behavior than the polymeric inserts, this results have been a baseline to the selection of new materials.

\section{NEW MATERIALS PENETRATION TESTS}

As it was proved in the previous sub-chapter, metallic materials can easily meet the required specifications and standards for these components. The main challenge focuses on finding polymeric materials that combine low thickness, good flexibility and good anti-penetration behavior.

Due to some of their properties like flexibility, light weight and their good mechanical properties aramid fiber, polypropylene and ultra-high molecular weight polyethylene based materials were selected and tested according to the standards. The results of those tests were helpful to conclude if those materials were suitable options for the new insert.

As it can be seen in Figure 3, it was able to conclude that the use of the referred materials alone would not be an option due to their unsatisfactory penetration resistance forces. Therefor combinations of those materials according to their prices and availability were made. Materials A, E, F, G and H were combined and tested to penetration (Figure 3 ).

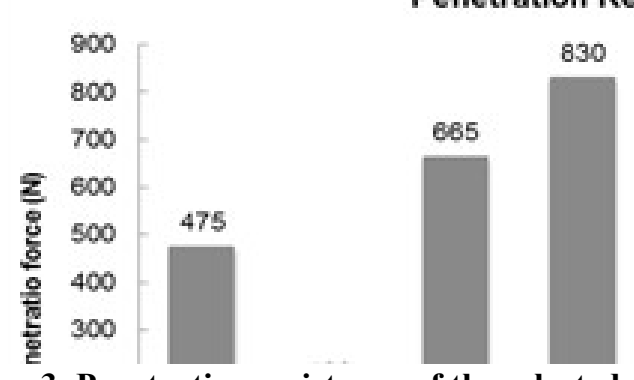

Figure 3. Penetration resistance of the selected materials.

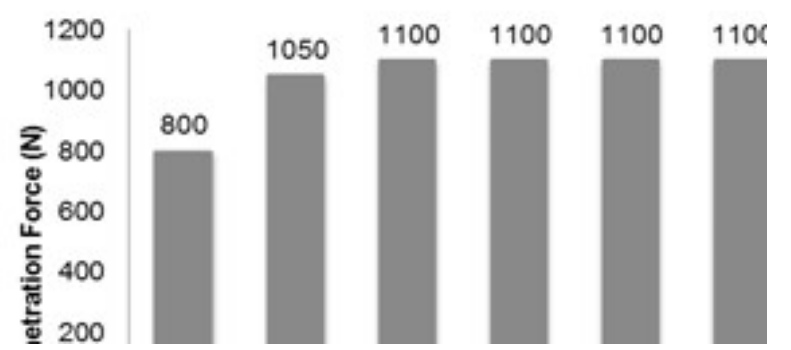

Figure 4. Penetration resistance of the selected materials combinations.

The results of tests on new materials show that none of them presents the penetration resistance required in the standards. However the graph in Figure 4 shows that when they are combined, they attain much more satisfactory results. Thus, the combination of materials by layers is an option for the final conceptual solution.

\section{PROPOSAL PENETRATION RESISTANT INSERT}

The proposed hybrid penetration resistant insert is shown in Figure 5. This component consists of multiple layers of different materials that combined together perform a high protection and a good sense of comfort. The combination of different materials ensures the protection against several injuries in heel and metatarsal zone without despising the reliability and anti-penetration behavior.

All materials have different well-defined functions, $\mathrm{C}$ and D materials are responsible for increasing the comfort, antifungal and energy distribution in the back area of the insert. The materials $\mathrm{A}$ and $\mathrm{B}$ are responsible for the anti-penetration protection. Material A is a combination of innovative fibers previously assembled. This combination allows to have both anti-penetration protection and good flexibility. The material B corresponds to a stainless steel sheet which will ensure penetration resistant and anti-torsion in the back area of the foot.

Figure 5. Virtual representation of a proposal penetration resistant insert.

\section{CONCLUSIONS}

In past few years, the large number of work accidents continued to result in serious injuries to a large percentage of workers. Focused on the increase of healthiness, comfort and safety of the existing safety footwear, an analysis of this type of component footwear was performed and several penetration tests to evaluate resistant inserts were planned. This analysis enabled authors to conclude the existence of innovation opportunities in such protective insole component; a balance between a healthier, more comfortable and lightweight device and at the same time resistant and strong enough to surpass the normative test must be meet.

For an adequate optimization, several tests were performed on penetration resistant inserts samples and finally, a brand new hybrid concept is proposed which gives a clear improvement in terms of comfort and protection. This new insert is composed of different materials arranged in layers, it combines a good flexibility in the front area, impacts absorber in the back side, good resilience to compression and a low thickness. Despite all this new features and improvements, this insert can be manufactured without using complex processes. 
In resume it is proposed an innovative insertion regarding the combination of materials and existent manufacturing process and technology. Its application on currently safety footwear would make it more comfortable, healthier and may appeal an increasing use and a decreasing in the number of injuries caused by accidents at work.

\section{AKNOWLEDGEMENTS}

This work was financed through funding from the Vale Inovação project n²002/24148 (QREN) of Portuguese AdI Agency.

\section{REFERENCES}

Aleven \& W., A. A., 1994. Puncture Resistant Insole for Safety Footwear. Canada, US 5285583.

Battaglia, L., 2003. Metalic Insert for Working and Safety Shoes. Italia, EP 1354526 A1.

Commission of the European Communities, 2007. Communication From The Commission To The European Parliament, The Council, The European Economic And Social Committee And The Committee Of The Regions. Brussels.

Communities, E., 2004. Statistical analusis of socieconomic costs of accidents at work in the European Union. Luxembourg.

Costa, S. L., Silva, J. V., Peixinho, N. \& Mendonça, J. P., 2013. Innovative geometric redesign of safety footwear components using a reverse engineering approach. ASME.

EUROSTAT http://epp.eurostat.ec.europa.eu/(2013).

Goldcher, A. \& b, D. A., 2005. Chaussures de sécurité, de protection et de travail. EMC-Podologie, pp. 12-23.

Harrison, F. A., 1999. Puncture-Resistant and Impact Resistant Safety Shoe Insert. Canada, US 5996257.

INE, Instituto Nacional de Estatistica., http://www.ine.pt/(2013).

Okayasu, K., 1991. Shoe Insole. Estados Unidos, Patente US 5001848 .

Sartor, L., Callegari, M. \& Montemurro, A., 2011. Insole Having Puncture-resistant Properties for Safety Footwear. Estados Unidos, US 8082685 B2. 
